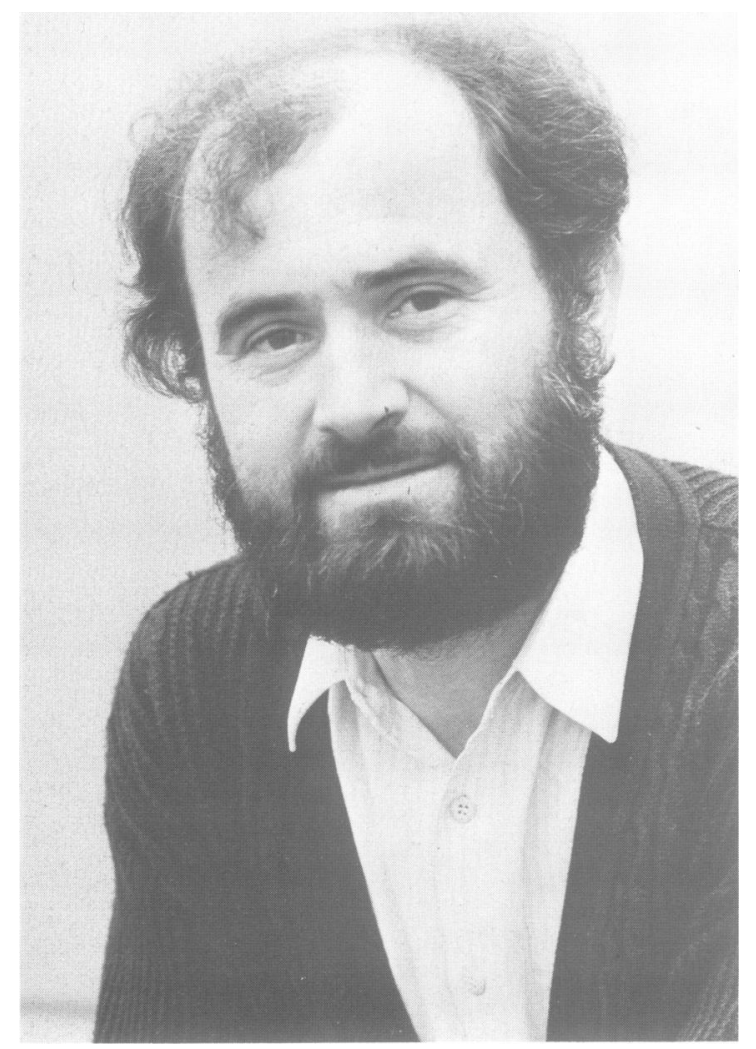

Professor Erwin Neher

\title{
NOBEL PRIZE FOR PHYSIOLOGY OR MEDICINE 1991
}

In this and the next issue we are pleased to be able to publish the Nobel lectures of Professor Erwin Neher and Professor Bert Sakmann, joint winners of the Nobel Prize for Physiology or Medicine in 1991. Both are members of the European Molecular Biology Organization. 


\section{NOBEL LECTURE}

\section{Ion channels for communication between and within cells}

\author{
Erwin Neher \\ Max-Planck Institut für biophysikalische Chemie. D-3400 Göttingen, \\ FRG
}

\section{Introduction}

Around 1970 the fundamental signal mechanisms for communication between cells of the nervous system were known. Hodgkin and Huxley (1952) had provided the basis for understanding the nerve action potential. The concept of chemical transmission at synapses had received its experimental verification by detailed studies on excitatory and inhibitory postsynaptic potentials (see Katz, 1986, for a concise description of the electrical signals in nerve and muscle). The question of the molecular mechanisms underlying these signals was still open, however. Hodgkin and Huxley (1952) used the concept of voltage-operated gates for a formal description of conductance changes, and by 1970 the terms Na-channel and K-channel were used frequently (see review by Hille, 1970), although no direct evidence for the existence of channels was available from biological preparations. This was different for the case of artificial membranes. Müller and Rudin (1963) introduced 'black-lipid membranes' as experimental model systems, which in many respects resemble the bimolecular lipid membrane of living cells. These membranes are rather good insulators. However, when they are doped with certain antibiotics or proteins they become electrically conductive. Bean $e t$ al. (1969) and Hladky and Haydon (1970) showed that some of these dopants induce discrete, steplike changes in conductance when they are added in trace amounts. All the evidence suggested that the conductance changes observed represent the insertion of single pore-like structures into the membranes.

Similar measurements in biological membranes were not possible at the time, since the methods available for recording currents in living cells typically had background noise levels higher by about a factor of a hundred than the 'singlechannel currents' observed in bilayers (see Figure 1). Indirect methods, however, provided strong evidence that channels similar in conductance to those in artificial membranes should be operative in nerve and muscle cells. Early attempts to count the number of Na-channels by tetrodotoxin binding indicated that the contribution of a single channel to $\mathrm{Na}$ conductance might be as much as $500 \mathrm{pS}$. Later, the technique of noise analysis (Katz and Miledi, 1972; Neher and Stevens, 1977) provided more accurate numbers. Anderson and Stevens (1973) estimated the conductance of single acetylcholine-activated channels (ACh-channels) at the frog neuromuscular junction to be $32 \mathrm{pS}$. This is close to the conductance of single gramicidin channels as measured by Hladky and Haydon (1970). Thus, it was very tempting to think about better methods for recording currents from biological preparations. There was good reason to hope that an improved technology would reveal a whole 'microcosmos' of electrical signals in a multitude of electrically and chemically excitable cell types. In this lecture I will give a short account of our joint effort to solve this problem, and then focus on further developments that the solution of the problem led to. Bert Sakmann, in the second lecture (Sakmann, 1992) will present some of the detailed knowledge that high-resolution current recording provides access to.

\section{Rationale for using 'patch pipettes'}

A basic limitation for any current measurement, disregarding instrumentation noise, is the 'Johnson' or thermal noise of the signal source, which for a simple resistor is given by

$$
\sigma_{n}=\sqrt{4 k T \Delta f / R}
$$

where $\sigma_{n}$ is the root-mean-square deviation of the current, $k$ is the Boltzmann constant, $T$ the absolute temperature, $\Delta f$ the measurement bandwidth, and $R$ the resistance. From this it is clear that the internal resistance of a signal source (or, more generally, the complex impedance) should be very high for low-noise current recording. Specifically, to record a current of $1 \mathrm{pA}$ at a bandwidth of $1 \mathrm{kHz}$ with $10 \%$ accuracy, the internal resistance of the signal source should be $\sim 2 \mathrm{G} \Omega$ or higher. We now know that the input resistances of small cells can be as high as that. But early in the seventies the conventional microelectrode techniques required large cells for reliable current measurements, and these typically had input resistances in the range $100 \mathrm{k} \Omega$ to $50 \mathrm{M} \Omega$. Thus, it seemed impossible to reach the required resolution with standard techniques and standard preparations. What was required, was a smaller signal source.

With these considerations in mind, we directed our efforts to isolate a small patch of membrane for the purpose of the electrical measurement. I had gained experience with suction pipettes being placed onto the surface of cells for local current measurement in the laboratory of H.D.Lux in Munich, where I did my doctoral thesis. Such pipettes had been used before in various contexts either for stimulation of cells or for current measurements (Pratt and Eisenberger, 1919; Strickholm, 1961; Frank and Tauc, 1963; Neher and Lux, 1969; Fishman, 1973). It was clear to us that they should be good tools for single-channel measurements, if only the 'pipette-to-membrane seal' could be made good enough. The impedance of the patch itself should be higher than required, even for a patch as large as $10 \mu \mathrm{m}$ in diameter. An incomplete seal, however, is 'seen' by the measuring amplifier in parallel to the patch, and its noise is superimposed onto the patch signal.

\section{Early single-channel measurements}

When Bert Sakmann and I started measurements by placing pipettes onto the surface of denervated muscle fibres, we soon realized that it was not so easy to obtain a satisfactory 


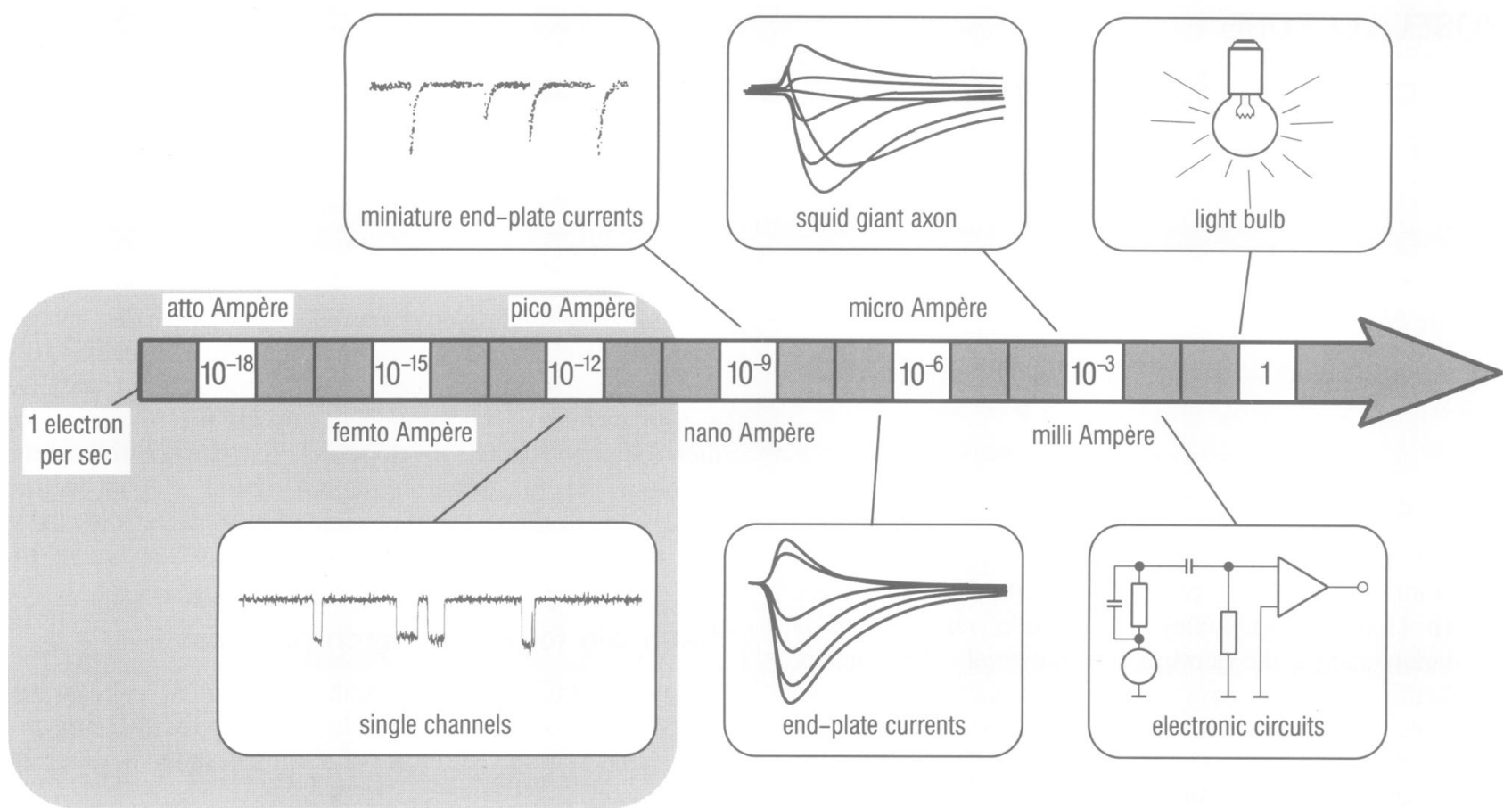

Fig. 1. A graphical representation of the quantity 'current' in logarithmic scale with representative examples of current signals or current-carrying elements from electronics and biology. The shaded region is that which was dominated by background noise before the development of the patch clamp technique.

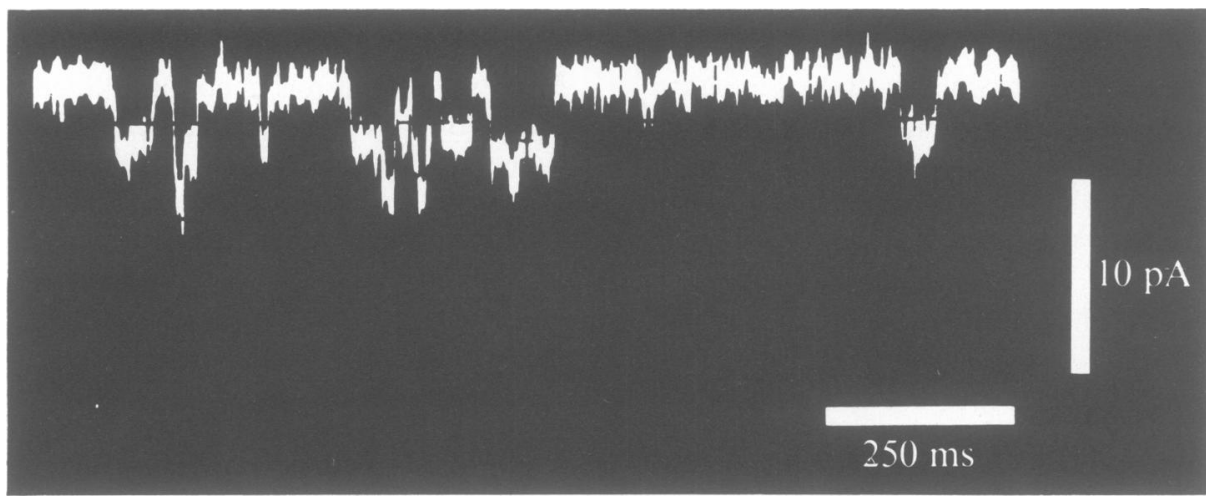

Fig. 2. Early single-channel currents from denervated frog (Rana pipiens) cutaneous pectoris muscle. The pipette contained $0.2 \mu \mathrm{M}$ suberyldicholine, an analogue of acetylcholine which induces very long-lived channel openings. Membrane potential, $-120 \mathrm{mV}$; temperature, $8^{\circ} \mathrm{C}$. Reproduced from Neher and Sakmann (1976).

'seal'. Although Bert Sakmann was very experienced in treating cell surfaces enzymatically through his work in B.Katz's laboratory, and although the work of Katz and Miledi (1972) and our own voltage-clamp measurements had shown that denervated muscle should have an appropriate density of diffusely dispersed ACh-channels, our initial attempts failed. Our seal resistances were just about 10-20 M , two orders of magnitude lower than desired. However, by reducing the pipette size and by optimizing its shape we slowly arrived at a point where signals emerged from the background-first some characteristic noise, later on blips which resembled square pulses, as expected. In 1976 we published records (Neher and Sakmann, 1976) which, with good confidence, could be interpreted as single-channel currents (see Figure 2). The fact that similar records could be obtained both in our Göttingen laboratory and in the laboratory of Charles F.Stevens at Yale (where I spent parts of 1975 and 1976), gave us confidence that they were not the result of some local demon, but rather signals of biological significance. The square-wave nature of the signals was proof of the hypothesis that channels in biological membranes open and close stochastically in an all-or-none manner. For the first time one could watch conformational changes of biological macromolecules in situ and in real time. However, the measurement was far from perfect. There still was excessive background noise, concealing small and more short-lived contributions of other channel types. Besides, the amplitudes of single-channel currents had a wide distribution, since the majority of channels were located under the rim of the pipette, such that their current contributions were recorded only partially.

We made many systematic attempts to overcome the seal problem (manipulating and cleaning cell surfaces, coating pipette surfaces, reversing charges on the glass surface etc.) with little success. Nevertheless some important properties of single channels were elucidated in the years 1975-1980 
$\mathrm{Na-channels}$

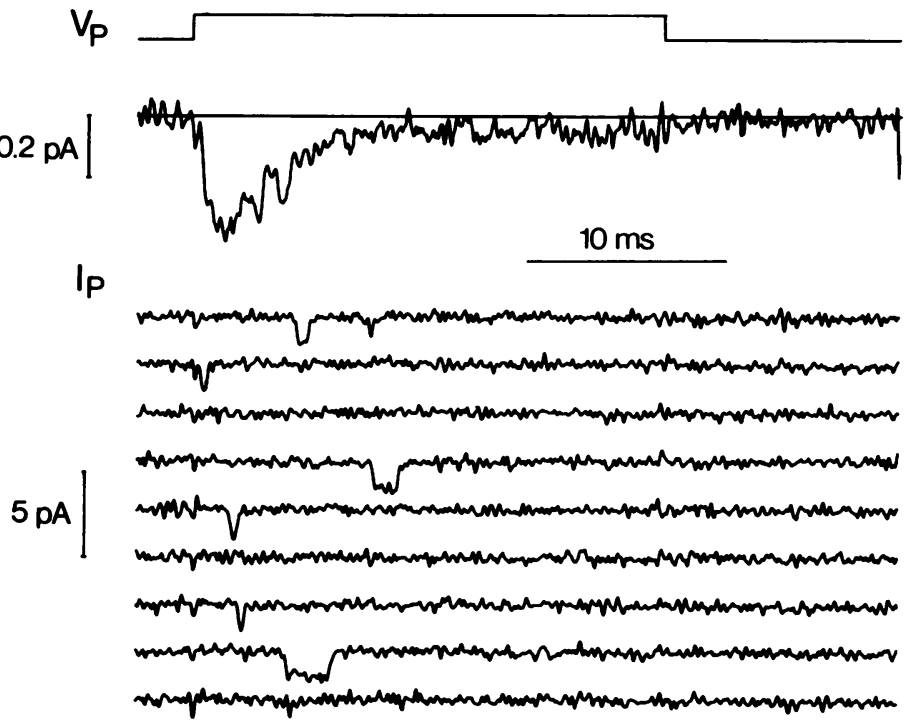

Ca-channels

$80 \mathrm{mV}$ dep.

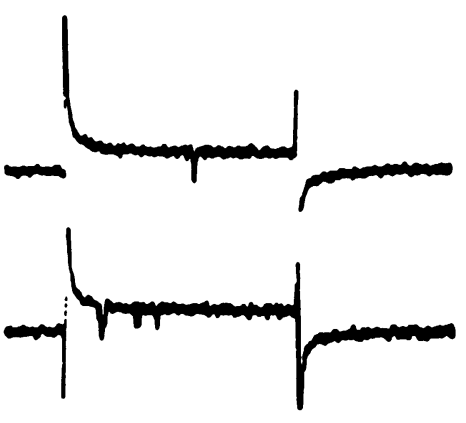

$50 \mathrm{mV}$ dep.

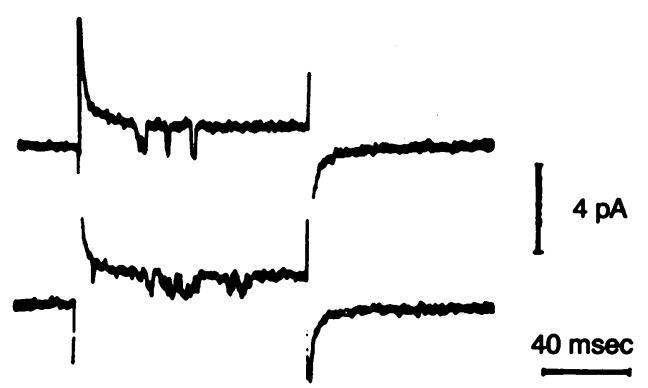

Fig. 3. Early records of voltage-activated single channels. The left side shows Na-channels (adapted from Sigworth and Neher, 1980). The top trace is the voltage protocol. The second trace shows the average response from 300 voltage pulse depolarizations, and the following traces give examples of individual responses. It is seen that in some-but not in all-traces there are individual openings (downward deflection) of $\mathrm{Na}$ channels. The patch was hyperpolarized by $30 \mathrm{mV}$, and $40 \mathrm{mV}$ depolarizing pulses are given. The right side shows individual Ca-channel currents (adapted from Fenwick et al., 1981). Depolarizing pulses as indicated were given from normal resting potential. The pipette contained isotonic Ba solution. Single channel responses are seen superimposed onto a residual capacitive and leak artefact. In the right panel these artefacts were digitally subtracted.

(Neher and Steinbach, 1978; Sakmann, 1978; Sakmann and Boheim, 1978; Conti and Neher, 1980; Sakmann et al., 1980).

By about 1980 we had almost given up on attempts to improve the seal, when we noticed by chance that the seal suddenly increased by more than two orders of magnitude when slight suction was applied to the pipette. The resulting seal was in the gigaohm range, the so-called 'Gigaseal'. It turned out that a Gigaseal could be obtained reproducibly when suction was combined with some simple measures to provide for clean surfaces, such as using a fresh pipette for each approach and using filtered solutions. The improved seal resulted in much improved background noise (Hamill et al., 1981). Fortunately, Fred Sigworth had just joined the laboratory. With his experience in engineering he improved the electronic amplifiers to match the advances in recording conditions. Thus, several types of ion channels could be characterized rapidly at good amplitude and time resolution (Figure 3).

\section{Unexpected benefits}

Solving the seal problem turned out not only to improve the electrical recording, but also to provide useful tools for manipulating patches and small cells. Although the physical nature of the 'Gigaseal' is still unknown, we soon realized that it provides not only electrical stability but also a tight mechanical connection between the measuring glass pipette and the membrane. Owen Hamill and Bert Sakmann (1981), simultaneously with Horn and Patlak (1980), found that patches could be removed from cells, simply by withdrawing the pipette. This results in 'excised patches', which are accessible for solution changes from both sides. Alternatively, a patch can be ruptured by a short pulse of suction or voltage without loss of the glass-to-membrane seal. Thus, an electrical connection is established between measuring pipette and cell, with the pipette-cell assembly well insulated against the outside bath. This configuration was termed 'whole-cell recording'. Figure 4 gives a schematic representation of the different procedures and resulting configurations.

Whole cell recording is very similar to conventional microelectrode impalement, with some important differences, however. (i) The leak between cell interior and bath is extremely small, such that this form of penetration is tolerated by cells as small as red blood cells (Hamill, 1983). (ii) The electrical access resistance is low (1-10 M 2 ) as compared with the electrode resistances of impalement electrodes (20-100 M , typically, for small cells). Thus, voltage-clamp conditions are achieved easily without feedback circuits and additional electrodes, if small cells are used (membrane resistance $100 \mathrm{M} \Omega-10 \mathrm{G} \Omega$ ). (iii) There is rapid diffusional exchange and equilibration between patch pipette and cell (Marty and Neher, 1983; Pusch and Neher, 1988). This provides control over the composition of the medium inside the cell. A cell can easily be loaded with ions, chelators, second messengers, fluorescent probes etc., simply by including these substances in the measuring pipette. 


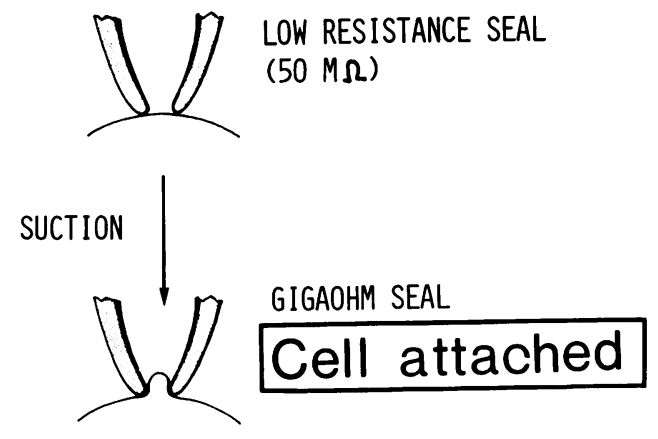

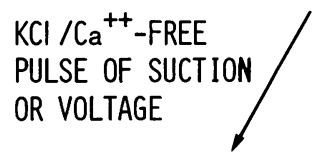
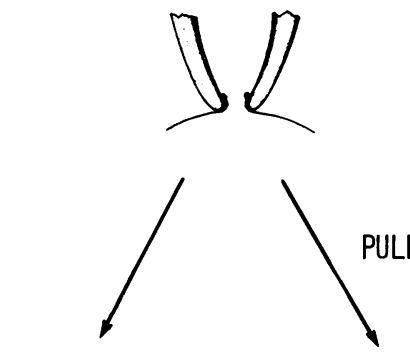

USING A SMALL CELL
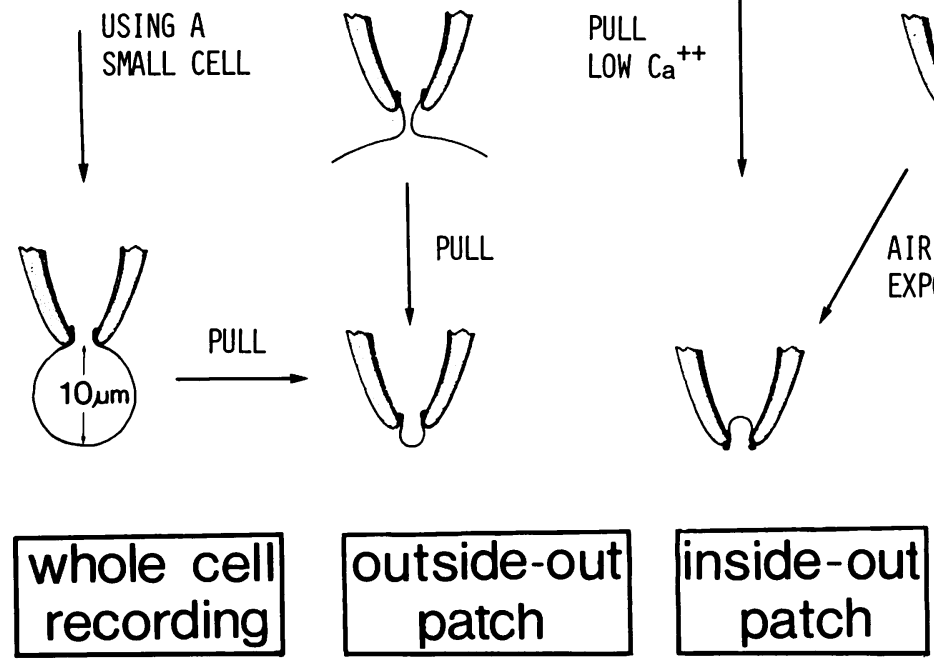

Fig. 4. Schematic representation of the procedures that lead to the different patch clamp configurations. From Hamill et al. (1981).

However, this exchange also implies that the internal milieu is disturbed, and that signalling cascades may be disrupted (see below).

With these properties, 'whole-cell recording' evolved to be the method of choice for recording from most cell-culture preparations and from acutely dissociated tissues. Many cell types, particularly small cells of mammalian origin, became accessible to biophysical analysis for the first time through whole-cell recording, since they would not tolerate multiple conventional impalements. Individual current types could be separated through control of solution composition on both sides of the membrane (Fenwick et al., 1982b; see Figure 5 for an example of whole-cell Ca-channel currents). This development shifted the emphasis of electrophysiological studies away from large-cell preparations, which usually were of invertebrate origin, towards mammalian and human cell types. In the first half of 1981 , just before we published a whole-cell characterization of a small mammalian cell (bovine adrenal chromaffin cells), only five out of 14 voltageclamp studies in the Journal of Physiology were performed on cells of mammalian origin. The first 1991 issue of the same journal alone contained 10 voltage-clamp studies on mammalian cells, none on invertebrates, and all using either the whole-cell or single-channel recording techniques.

\section{Disturbing second messenger equilibria}

All measurement techniques have to deal with a conflict with respect to their objectives. In some instances, it is desired to observe a process, disturbing it as little as possible; in other instances one would like to obtain quantitative data under as much experimental control as possible. The two aims are, of course, mutually exclusive. The cell-attached measurement comes close to the first ideal, since it leaves the cell largely intact, and allows one to observe channels open and close, or to record action potentials extracellularly 
A

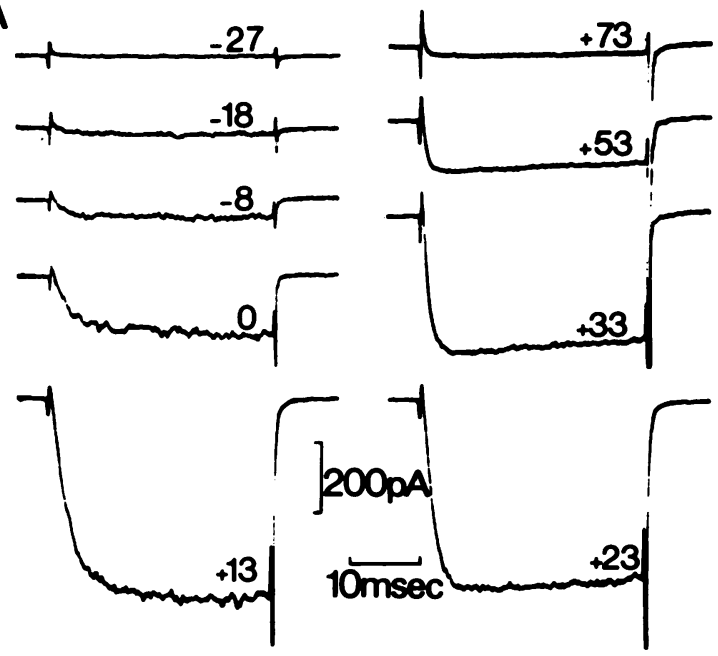

B

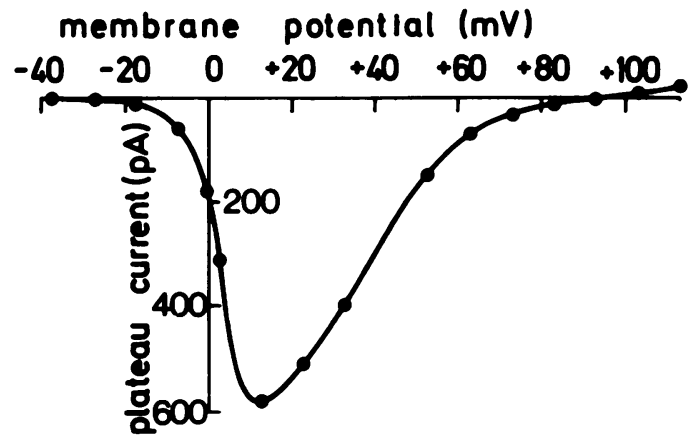

Fig. 5. Whole cell membrane currents in chromaffin cells bathed in isotonic Ba solution plus $20 \mu \mathrm{g} / \mathrm{ml}$ TTX. The membrane potential was stepped to values as indicated from a holding potential of $-67 \mathrm{mV}$. The pipette solution contained mainly $\mathrm{CsCl}$ and TEA. With this solution composition the currents flowing are predominantly carried by Ca-channels. Part B shows the current-voltage relationship. Reproduced from Fenwick et al. (1982b).

(Fenwick et al., 1982a). Excised patches constitute the other extreme, where membrane patches are removed from their natural environment for optimal control of solution composition on both sides of the membrane. The whole-cell recording method is at an intermediate position in this respect. It does provide excellent control over membrane potential, if cells $<20 \mu \mathrm{m}$ in diameter are used. However, the chemical composition of the internal medium is neither undisturbed nor under good control. We found that small mobile ions typically exchange by diffusion between pipette and cell in a few seconds (for cells of $\sim 15 \mu \mathrm{m}$ diameter and pipettes of 2-5 $\mathrm{M} \Omega$ resistance). Molecules of intermediate size, like second messengers, typically 'wash-out' or 'load' cells within $10 \mathrm{~s}$ to $1 \mathrm{~min}$, and small regulatory proteins may take several minutes and longer for complete equilibrium (Pusch and Neher, 1988).

In retrospect, it seems fortunate that we started our measurements with ACh-channels and Na-channels, which happen to be relatively robust with regard to diffusible regulatory components. Thus we initially avoided complications of 'channel modulation'. However, when switching to channels which are now known to be subject to modulation by second messengers, G-proteins and phosphorylation (such as Ca-channels), we soon realized that channel activity would disappear rapidly as a result of the perturbation imposed by the measurement, both in 'whole-cell' and, more so, in excised-patch measurements (Fenwick et al., 1982b). Such 'washout' had been observed earlier in studies on dialysed giant neurones (Kostyuk, 1980). The prototype of a channel modulated by an intracellular second messenger, the Ca-activated K-channel was characterized by Alain Marty (1981). These early studies already showed the ambivalent nature of the new tools: on the one hand there was the advantage of control over intracellular calcium to eludicate the mechanism of Ca-modulation, and on the other hand there was the loss of cellular function due to the loss of regulators, which at that time were unknown. Subsequently, ingenious use of these tools by many laboratories has revealed a whole network of interactions between channels, second messengers, G-proteins and other regulatory proteins (see Hille, 1989, for review). In order to uncover this network it was necessary not only to record electrically from cells, but also to control or change systematically the concentrations of second messengers (Marty, 1981; Kameyama et al., 1986; Penner et al., 1988; Fesenko et al., 1985). Later on it became possible to impose step-like changes in regulators using caged compounds (Morad et al., 1988) or to load cells with fluorescent indicator dyes (Almers and Neher, 1985) and regulatory proteins (Hescheler $e t$ al., 1986).

All this was made possible by utilizing diffusional exchange between patch pipette and cell or by exposing the cytoplasmic surface of excised patches. Later, ways were found to avoid the adverse effects of 'washout' by making the patch selectively permeable to small ions (Lindau and Fernandez, 1986; Horn and Marty, 1988). This technique, at present, seems to be the least invasive method for studying the functioning of small cells.

\section{An electrophysiological approach to study secretion}

An outstanding property of electrical measurement with gigasealed pipettes is its high sensitivity. This can be used not only to record currents, but also to study the membrane electrical capacitance, which is a measure of cell surface area. It had been observed before that membrane capacitance increases under conditions where massive exocytosis of secretory vesicles is expected to occur. Presumably, this is due to the incorporation of vesicular membrane into the plasma membrane (Jaffe et al., 1978; Gillespie, 1979). The low background noise of the Gigaseal measurement made it possible to resolve area changes which result from the exocytotic fusion of single vesicles. This was shown by Neher and Marty (1982) for exocytosis from chromaffin cells of the adrenal medulla and by Fernandez et al. (1984) for secretion of histamine from rat peritoneal mast cells. In the latter case, the granules are somewhat larger, leading to well resolved step-like increases in capacitance (see Figure 6). These records show that capacitance measurement is a highresolution technique. The figure also shows, however, that capacitance is not a very specific measure for secretion. This is evident from the fact that there is a continuous, smooth decrease in capacitance before exocytotic events show up. We found (Almers and Neher, 1987) that the rate of this decrease depends on the concentration of free intracellular calcium $[\mathrm{Ca}]_{\mathrm{i}}$ and that it has many properties expected for pinocytosis.

We used capacitance measurement together with current recording and microfluorimetry (fura-2) to study simul- 


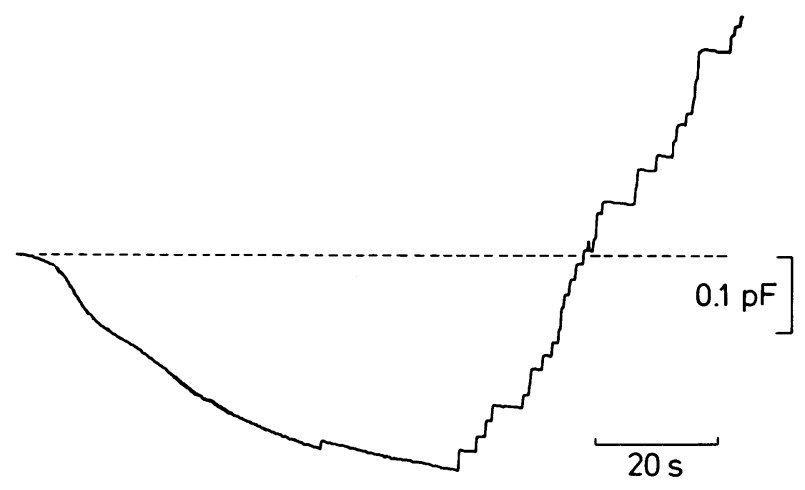

Fig. 6. High resolution capacitance recording during the onset of a mast cell degranulation. Whole-cell recording from a rat peritoneal mast cell with a pipette containing $20 \mu \mathrm{M}$ GTP- $\gamma$-S. Initially the capacitance slowly decreased, probably due to retrieval of very small pinocytotic vesicles. After some delay degranulation started, leading to a staircase-like increase in capacitance, each step representing fusion of a single granule (adapted from Almers and Neher, 1987).

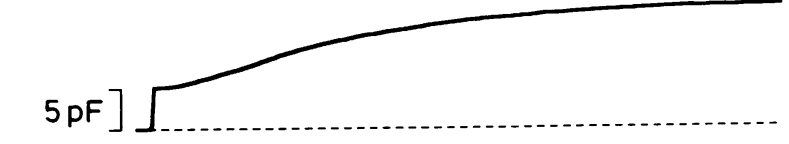

A
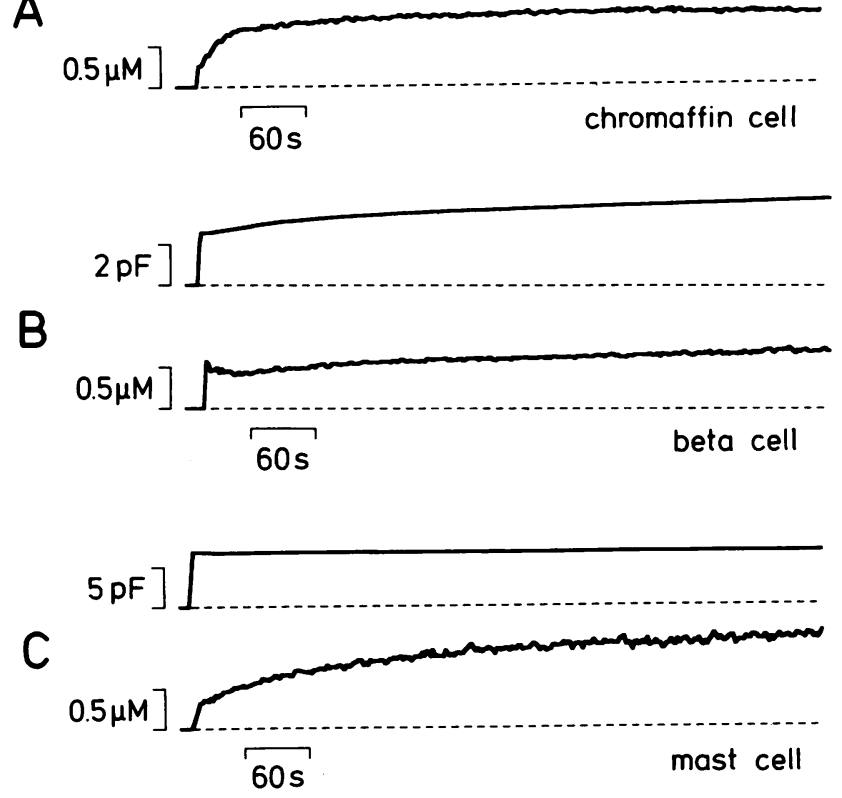

Fig. 7. Different effectiveness of intracellular free calcium in inducing a capacitance increase. Part $\mathbf{A}$ represents a measurement from a bovine chromaffin cell. The traces represent the time courses of capacitance (top) and free calcium concentration (bottom; measured by fura-2 fluorescence) following a whole-cell penetration Calcium rapidly rises, since the pipette was filled with a Ca-EGTA mixture adjusted for free calcium of $\sim 1 \mu \mathrm{M}$. On the capacitance trace the step at the beginning $(\approx 6 \mathrm{pF})$ represents the initial capacitance of the cell, which becomes 'visible' at the moment of 'break in'. Capacitance then rises $\sim 2$ - to 3-fold due to exocytosis Part B shows a similar measurement on a pancreatic $\beta$ cell, with only little capacitance increase, and part $\mathbf{C}$ shows the complete lack of response in rat peritoneal mast cell. Reproduced from Penner and Neher (1988).

taneously, in a single cell, changes in $[\mathrm{Ca}]_{\mathrm{i}}$ and secretion at subsecond time resolution. We were surprised to find quite a difference in the effectiveness of regulators of secretion in different cell types (Figure 7). For chromaffin cells, which in many respects resemble neurones, the classical role of calcium as prime regulator of secretion was fully c.:-ifirmed
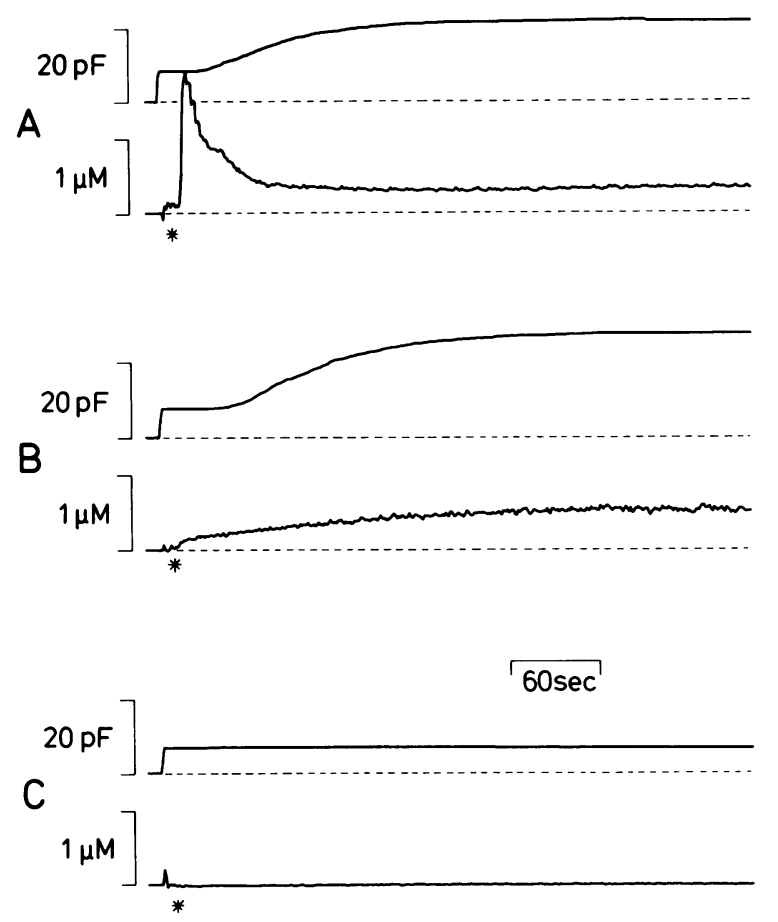

Fig. 8. Responses of mast cells to stimulation by the secretagogue compound 48/80 under different Ca-buffering conditions. The individual panels show combined capacitance-calcium (fura-2) measurements similar to those of Figure 7. Panel $\mathbf{A}$ shows the 'unbuffered' case. No Ca-buffer was added to the pipette (except for $100 \mu \mathrm{M}$ fura-2). A Ca-transient developed in response to stimulation (asterisk). Secretion typically proceeded mainly during the falling phase of the Ca-transient or following it. In Panel B an EGTA-Ca mixture $(10 \mathrm{mM})$ was added to the pipette which suppressed the transient, and fixed the Ca concentration to the range $200-500 \mathrm{~nm}$. Nevertheless, secretion proceeded with a time course similar to that in case A. In panel C $10 \mathrm{mM}$ EGTA was added to clamp calcium to low values. This suppressed both the Ca signal and the secretory response (from Neher and Penner (1988).

(Augustine and Neher, 1992). In mast cells, however, which are not electrically excitable, changes in calcium concentration (in the physiological range) had little effect. Ca-independent secretion had been described in a number of inexcitable cell types (Haslam and Davidson, 1984; Sha'afi et al., 1983; Di Virgilio et al., 1984). But for us, who were used to working with electrically excitable cells, it was a shock not to be able to elicit secretion with an intracellular solution buffered to $\sim 1 \mu \mathrm{m}$ free calcium. Initially, we hypothesized that the whole-cell configuration resulted in a loss of $\mathrm{Ca}$-dependent regulators by washout-in analogy to early work on muscle contraction in skinned fibres. Later, we learned that cells in the whole-cell recording configuration were still able to secrete in response to GTP- $\gamma-S$, a nonhydrolysable analogue of GTP (Fernandez et al., 1984). With this response in hand, it was possible to show that calcium, although not able to elicit secretion by itself, was still effective in accelerating an ongoing secretory response. There was no indication of a loss of a Ca-regulator; rather it appeared that the GTP- $\gamma-S$ stimulus primed the cell to render it more Ca-sensitive (Neher, 1988).

GTP- $\gamma-S$ nonspecifically activates intracellular signal pathways, most prominently the dual-signal pathway (Cockcroft and Gomperts, 1985; Berridge and Irvine, 1989). Using the repertoir of patch clamp methods Penner (1988) was able to show that various external secretagogoues, which are also known to activate the dual signal pathway, lead to 
a characteristic pattern of secretion. This is accompanied by IP $_{3}$-induced $\mathrm{Ca}$ release from intracellular stores. Combining the fura- 2 technique with patch clamping one can study the temporal relationship between this prominent transient $\mathrm{Ca}$ signal and secretion. In spite of the modulatory effect of calcium described above it was found that there is no strict correlation. The secretory response very often starts well after the peak of the $\mathrm{Ca}$ signal. Also, the Ca peak can be abrogated by including EGTA in the patch pipette without drastic effects on secretion (Figure 8). Phenomenologically this can be explained by the fact that the Ca peak occurs very early at a time when the above-mentioned priming effect of a chemical stimulus has not occurred yet. A sustained phase of increased calcium, which very often follows the Ca-release peak, is more efficient in accelerating secretion, however, since it is more appropriately timed. In terms of molecular mechanisms, the priming is likely to represent protein kinase C activation (Heiman and Crews, 1985; Penner, 1988). Additionally it has been shown that there is another G-protein-mediated pathway, which links a hormonal stimulus to secretion (Gomperts et al., 1986; Penner, 1988). This link is sensitive to pertussis toxin, and to intracellular application of cAMP (Penner, 1988).

Our studies on mast cells (see Penner and Neher, 1989 for review) have taught us that secretory control is not necessarily dominated by calcium, but rather that it involves a meshwork of interacting second messenger pathways. In neurones, it appears that changes in calcium (Augustine et al., 1987) or calcium plus voltage (Parnas et al., 1986) largely determine the kinetics of fast secretory events. However, there is increasing evidence that other second messengers are responsible for plastic changes in synaptic signals, possibly by regulating the availability of vesicles for secretion (Llinas et al., 1991). Unfortunately nerve terminals are usually not accessible to the kind of biophysical investigations as described here. However, recent studies on neurosecretory cells reveal new details on the kinetics of Ca-induced secretion (Thomas et al., 1990; Augustine and Neher, 1992; Lim et al., 1990; Lindau et al., 1992). They promise to allow a differentiation between the exocytotic event per se and some of the other steps in the life cycle of a secretory vesicle. Together with the ability to control second messengers such studies may soon lead to a better understanding of exocytosis and of the molecular processes that direct a vesicle to its site of action.

\section{Acknowledgements}

I am deeply indebted to my teacher in electrophysiology, H.D.Lux, who focussed the young physics student's mind onto ion channels, and taught me to use microscopic tools. Superb working facilities in Göttingen were provided by H.Kuhn, O.D.Creutzfeldt and T.Jovin, who established a Young Investigators Laboratory for Bert Sakmann, F. Barrantes and myself where we could independently pursue our goals. In more recent years my work was generously supported by a Leibniz Award of the Deutsche Forschungsgemeinschaft.

\section{References}

Almers,W. and Neher,E. (1985) FEBS Lett., 192, 13-18. Almers,W. and Neher,E. (1987) J. Physiol., 386, 205-217. Anderson,C.R. and Stevens,C.F. (1973) J. Physiol., 235, 655-691. Augustine,G.J. and Neher,E. (1992) J. Physiol., 450, 247-271.

Augustine,G.J., Charlton,M.P. and Smith,S.J. (1987) Annu. Rev. Neurosci., 10, 633-693.

Bean,R.C., Shepherd,W.C., Chan,H. and Eichler,J.T. (1969) J. Gen. Physiol., 53, 741-757.
Berridge,M.J. and Irvine,R.F. (1989) Nature, 341, 197-205.

Cockcroft,S. and Gomperts,B.D. (1985) Nature, 314, 534-536.

Conti,F. and Neher,E. (1980) Nature, 285, 140-143.

Di Virgilio,F., Lew,D.P. and Pozzan,T. (1984) Nature, 310, 691-693.

Fenwick,E.M., Marty,A. and Neher,E. (1981) J. Physiol., 319, 100P-101P.

Fenwick,E.M., Marty,A. and Neher,E. (1982a) J. Physiol., 331, 577-597. Fenwick,E.M., Marty,A. and Neher,E. (1982b) J. Physiol., 331, 599-635.

Fernandez,J.M., Neher,E. and Gomperts,B.D. (1984) Nature, 312, $453-455$

Fesenko,E.E., Kolesnikov,S.S. and Lyubarsky,A.L. (1985) Nature, 313, 310-313.

Fishman,H.M. (1973) Proc. Natl. Acad. Sci. USA, 70, 876-879.

Frank,K. and Tauc,L. (1963) In Hoffman,J. (ed.), The Cellular Function of Membrane Transport. Prentice Hall, Englewood Cliffs, NJ.

Gillespie,T.J. (1979) Proc. R. Soc. London B, 206, 293-306.

Gomperts,B.D., Barrowman,M.M. and Cockcroft,S. (1986) Fed. Proc., 45, 2156-2161.

Hamill,O.P., (1983) In Sakmann,B. and Neher,E. (eds), Single Channel Recording. Plenum Press, New York, pp. 451-471.

Hamill,O.P. and Sakmann,B. (1981) J. Physiol., 312, 41P-42P.

Hamill,O.P., Marty,A., Neher,F., Sakmann,B. and Sigworth,F.J. (1981) Pflügers Arch., 391, 85-100.

Haslam,R.J. and Davidson,M.L. (1984) FEBS Lett., 174, 90-95.

Heiman,A.S. and Crews,F.T. (1985) J. Immunol., 134, 548-554.

Hescheler,J., Kameyama,M. and Trautwein,W. (1986) Pflügers Arch., 407, $182-189$.

Hille,B. (1970) Prog. Biophys. Mol. Biol., 21, 1-32.

Hille,B. (1989) Q. J. Exp. Physiol., 74, 785-804.

Hladky,S.B. and Haydon,D.A. (1970) Nature, 225, 451-453.

Hodgkin,A.L. and Huxley,A.F. (1952) J. Physiol., 117, 500-544.

Horn,R. and Marty,A. (1988) J. Gen. Physiol., 92, 154-159.

Horn, R. and Patlak,J. (1980) Proc. Natl. Acad. Sci. USA, 77, 6930-6934.

Jaffe,L.A., Hagiwara,S. and Kado,R.T. (1987) Dev. Biol., 67, 243-248.

Katz,B. (1966) Nerve, Muscle and Synapse. McGraw-Hill, New York.

Kameyama,M., Hescheler,J., Hofmann,F. and Trautwein,W. (1986) Pflügers Arch., 407, 123-128.

Katz,B. and Miledi,R. (1972) J. Physiol., 224, 665-700.

Kostyuk,P.G. (1980) Neuroscience, 5, 945-959.

Lim,N.F., Nowycky,M.C. and Bookman,R.J. (1990) Nature, 334, $449-451$

Lindau,M. and Fernandez,J.M. (1986) Nature, 319, 150-153.

Lindau,M., Stuenkel,E.L. and Nordmann,J.J. (1992) Biophys. J., in press.

Llinas,R., Gruner,J.A., Sugimori,M., McGuiness,T.L. and Greengard,P. (1991) J. Physiol., 436, 257-282.

Marty,A. (1981) Nature, 291, 497-500.

Marty,A. and Neher,E. (1983) In Sakmann,B. and Neher,E. (eds), Single Channel Recording. Plenum Press, New York, pp. 107-122.

Morad,M., Davies,N.W., Kaplan,J.H. and Lux,H.D. (1988) Science, 241, $842-844$

Müller,P. and Rudin,D.O. (1963) J. Theor. Biol., 4, 243-280.

Neher,E. (1988) J. Physiol., 395, 193-214.

Neher,E. and Lux,H.D. (1969) Pflügers Arch., 311, 272-277.

Neher,E. and Marty,A. (1982) Proc. Natl. Acad. Sci. USA, 79, 6712-6716.

Neher,E. and Penner,R. (1988) In Thorn,N.A., Treiman,M. and Petersen,O.H. (eds), Molecular Mechanisms in Secretion. Munksgaard, Copenhagen, pp. 262-270.

Neher,E. and Sakmann,B. (1976) Nature, 260, 799-802.

Neher,E. and Steinbach,J.H. (1978) J. Physiol., 277, 153-176.

Neher,E. and Stevens,C.F. (1977) Annu. Rev. Biophys. Bioeng., 6, 345-381.

Parnas,H., Dudel,J. and Parnas,I. (1986) Pflügers Arch., 406, 121-130.

Penner,R. (1988) Proc. Natl. Acad. Sci. USA, 85, 9856-9860.

Penner,R. and Neher,E. (1988) J. Exp. Biol., 139, 329-345.

Penner,R. and Neher,E. (1989) Trends Neurosci., 12, 159-163.

Penner,R., Matthews,G. and Neher,E. (1988) Nature, 334, 499-504.

Pratt,F.H. and Eisenberger,J.P. (1919) Am. J. Physiol., 49, 1-54.

Pusch,M. and Neher,E. (1988) Pflügers Arch., 411, 204-211.

Sakmann,B. (1978) Fed. Proc., 37, 2654-2659.

Sakmann,B. (1992) EMBO J., 11, in press.

Sakmann,B. and Boheim,G. (1978) Nature, 282, 336-339.

Sakmann,E., Patlak,J. and Neher,E. (1980) Nature, 286, 71-73.

Sha'afi,R.I., White,J.R., Molski,T.P.F., Shefcyk,J., Volpi,M., Naccache,P.H. and Feinstein,M.B. (1983) Biochem. Biophys. Res. Commun., 114, 638-645.

Sigworth,F.J. and Neher,E. (1980) Nature, 287, 447-449.

Strickholm,A. (1961) J. Gen. Physiol., 44, 1073-1087.

Thomas,P., Suprenant,A. and Almers,W. (1990) Neuron, 5, 723-733. 